\title{
DESEMPENHO PRODUTIVO DA RACA PITANGUEIRAS (5/8 RED POLL X 3/8 GUZERÁ) E DE CRUZAMENTO RED POLL X ZEBU NO TRÓPICO BRASILEIRO.
}

\author{
Raysildo Barbosa LŌBO* \\ Francisco A. Moura DUARTE ${ }^{\star *}$
}

\begin{tabular}{ll} 
& $\mathrm{RFMV}-\mathrm{A} / 34$ \\
\hline
\end{tabular}

LÔBO, R.B. \& DUARTE, F.A.M. Desempenho produtivo da raça Pitangueiras (5/8 Red Poll $x$ 3/8 Guzerá) e de cruzamento Red Poll $x$ Zebu no trópico brasileiro. Rev. Fac. Med. vet. Zootec. Univ. S. Paulo, 14(2): 315-323, 1977.

RESUMO: Foi avaliada a capacidade produtiva, em regiâo tropical, de fêmeas da raça Pitangueiras e de cruzamentos Red Poll $x$ Zebu. Foram analisados dados de 851 bovinos assim distribuidos: 234 vacas $1 / 2$ Red Poll $x$ Zebu, 394 vacas $1 / 4$ Red Poll $x 3 / 4$ Guzerá e 223 vacas 5/8 Red Poll $\times 3 / 8$ Guzerá. Pelo método dos quadrados mínimos, testou-se o efeito de fatores de ambiente sobre a produção de leite, da primeira à quarta lactação. As médias da produção de leite à primeira lactação (padronizada para 256 dias), foram de $1767 \mathrm{~kg}(\mathrm{C.V} .=20 \%) ; 1605 \mathrm{~kg}(\mathrm{C} . \mathrm{V} .=24 \%)$ e $242 \mathrm{l} \mathrm{kg}(\mathrm{C} . \mathrm{V} .=16 \%)$, respectivamente, para as vacas, $1 / 2$ Red Poll $x 1 / 2$ Zebu, 1/4 Red Poll x 3/4 Guzerá e 5/8 Red Poll x 3/8 Guzerá. A máxima produção foi alcançada na quarta, sexta e quinta lactação, com aumentos consecutivos de $32 \%$, $37 \%$ e $23 \%$, respectivamente, para os bovinos referidos anteriormente. A produção de leite, à primeira lactação, foi influenciada significativame'nte pela idade da vaca e ano do parto. A época do parto somente afetou significativamente a produção de leite nas vacas $1 / 2$ Red Poll $x$ 1/2 Zebu. As estimatiuns do coeficiente de repetibilidade para os grupos genéticos $1 / 2$ Red Poll $x / / 2$ Zebu, I/4 Red Poll $x 3 / 4$ Zebu e $5 / 8$ Red Poll $x 3 / 8$ Guzerá foram $0,15 \pm 0,03 ; 0,36 \pm 0,03$ e $0,24 \pm 0,04$, respectivamente.

UNITERMOS: Leite, produção"; Raça Pitangueiras *; Bovinos, cruzamento "; Duração da lactaçāo.

\section{INTRODUÇÃO}

Uma das dificuldades encontradas pela pecuária leiteira nos países tropicais é a escoIha da raça para exploração útil e econômica. E sabido que as raças de regiões temperadas e especializadasi para a produção de leite, apresentam baixa adaptação quando mantidas em clima tropical, havendo ainda uma redução acentuada na produção de acordo com o aumento da temperatura ambiente (KASSIR; JUMA e AL-JAFF ${ }^{7}$; KNUDSEN e SOHAEL ${ }^{8}$ ).
Estudos realizados com estas raças no Brasil e em outros países tropicais, mostraram que os animais não são capazes de apresentar os mesinos rendimentos dos países de origem. Por outro lado. raças autóctones e adaptadas aos trópicos, não possuem capacidade de produção leiteira. A solução desses problemas poderá ser encontrada no melhoramento genético do gado nacional ou na seleção das raças européias para maior tolerância ao calor. Estas duas correntes de opiniões são levantadas freqüientemente por grande número de pesquisadores: (BRAN-

* Professor Assistente Doutor.

Departamento de Produção Animal. Faculdade de Medicina Veterinária e Zootecnia da USP.

-. Professor Livre-Docente.

Faculdade de Medicina de Ribeirão Preto, USP. 
TON, McDOWELL E BROWN ${ }^{2}$; MARPLES e TRAIL ${ }^{10}$; TRAIL e MARPLES ${ }^{13}$ ). Por outro lado, existem ainda aqueles que acreditam na criação de novos genótipos, através do cruzamento de zebuínos $x$ taurinos, isto é, reunir numa nova raça os genes de alta produção dos taurinos e aqueles responsáveis pela rusticidade dos zebuínos (KASSIR, JUMA e AL-JAFF ${ }^{7}$; KNUDSEN e SOHAEL ${ }^{8}$; $\mathrm{LOBO}^{9}$ ).

o S.A. Frigorífico Anglo pensando em reunir essas duas características num mesmo bovino iniciou em 1942, no Estado do Rio de Janeiro, o cruzamento de Red Poll x Zebu com a finalidade de desenvolver para as condições tropicais brasileiras uma raça que tivesse alta produção de leite, bom desenvolvimento ponderal e qualidades de adaptação ao meio. $\hat{\mathrm{E}}$ objetivo do presente trabalho avaliar o desempenho produtivo e determinar coeficientes de repetibilidade da produção de leite da raça Pitangueiras e de cruzamento Red Poll x Zebu.

\section{MATERIAL E MÉTODO}

\section{Animais e Manejo}

Os dados utilizados no presente trabalho foram obtidos na Fazenda Três Barras, pertencente ao S.A. Frigorífico Anglo, distante $2 \mathbf{k m}$ de Pitangueiras, cidade localizada no norte do Estado de São Paulo. A fazenda possui uma área cultivada de 6.534 hectares, dos quais 2.094, plantados com capimocolonião (Panicum maximum, L.) e pangola ( $D i$ gitaria decumbens, $\mathrm{L}$.)

A fazenda está situada a uma altitude de 503 metros, a $21^{\circ} 00^{\prime}$ de latitude sul e $48^{\circ} 41^{\prime}$ de longitude oeste de Greenwich. $O$ clima é tropical úmido, do tipo Aw da classificação de Köeppen, com invernos secos. A temperatura média anual é de $24^{\circ} \mathrm{C}$ e a precipitação de cerca de $1.346 \mathrm{~mm}$ distribuídos em duas épocas distintas, isto é, $1.157 \mathrm{~mm}$ nos meses de outubro a março e $189 \mathrm{~mm}$ de abril a setembro.

Foram analisadas 3.559 lactações oriundas de 851 vacas do atual rebanho Pitangueiras, com a seguinte constituição genética: 234 vacas $1 / 2$ Red Poll x 1/2 Zebu, 394 . vacas 1/4 Red Poll x 3/4 Guzerá e 223 vacas 5/8 Red Poll x $3 / 8$ Guzerá (raça Pitangueiras). Durante a época de pasto abundante o rebanho não recebeu suplementação. $\mathrm{Na}$ época de seca invernal, as vacas em lactação recebiam $1 \mathrm{~kg}$ de concentrado (com $16 \%$ de proteína bruta) para cada 3 a $4 \mathrm{~kg}$ de leite produzido, dependendo também do estado do pasto. Além disso, recebiam diariamente, de 15 de junho a 15 de outubro, $1 \mathrm{~kg}$ de melaço enriquecido com uréia, na produção de 9:1 em cochos especiais.

O controle sanitário do rebanho era feito através de vacinações sistemáticas contra carbúnculo sintomático, brucelose, aftosa e paratifo. As provas para o diagnóstico da brucelose e tuberculose, nas matrizes, foram realizadas semestralmente, separando-se os reagentes. $\mathrm{Os}$ bezerros foram tratados com vermífugos de 4 em 4 meses e, atualmente, é feito o exame periódico das fezes.

Médias e Medidas de Variabilidade

Num estudo preliminar foi calculada a média aritmética, desvio padrão, erro padrão da média e coeficiente de variação da produção de leite e da duração da lactação dos grupos genéticos mencionados.

0 conhecimento da extensão média da lactação serviu para padronizar a produção de leite de cada vaca, antes de se avaliar a influência de outras fontes de variação.

A expressão usada para padronizar a produção de cada vaca foi:

$$
\text { L } \times 256 \text { dias }
$$

\section{D}

onde:

L: produção de leite por lactação (kg);

D: duração da lactação (dias).

Determinação da significância estatística das fontes de variação

Os efeitos de idade da vaca, época e ano do parto foram estimados através da análise dos quadrados mínimos (HARVEY ${ }^{5}$ ), de acordo com o modelo linear:

$$
Y_{i j k l}=\mu+a_{i}+\beta_{j}+\psi_{k}+\epsilon_{i j k l}
$$


onde:

$Y_{\text {ijkl: }}$ Produção de leite por lactação padro nizada para 256 dias.

$\mu \quad$ :média geral

$a_{i}$ : efeito da idade da vaca $\mathrm{i}(\mathrm{i}=1,5)$.

$\beta_{j}$ : efeito da época do parto $\mathrm{j}(\mathrm{j}=1,2)$.

$\downarrow_{k}$ : efeito do ano do parto $k(k=1,18)$.

€̈jkl : "erro aleatório".

A época do parto foi dividida em duas, correspondendo ao periodo de seca invernal, de abril a setembro, e de chuvas, de outubro a março do ano seguinte. A idade da vaca no parto variou de 2 a 12 anos e foi dividida em intervalos de 12 meses, a fim de verificar sua influência sobre a produção de leite por lactação. Os efeitos do ano do parto foram estudados no periodo compreendido entre os anos de 1955 a 1972, (18 anos).

Determinação do coeficiente de repetibilidade

Este parâmetro fenotípico foi calculado para três grupos genéticos, após o ajuste dos dados para os efeitos mesológicos significativos, através das constantes dos quadrados mínimos.

O modelo linear proposto foi:

$$
\mathrm{Y}_{\mathrm{ij}}=\mu+\nu_{\mathrm{i}}+\epsilon_{\ddot{\eta}}
$$

O coeficiente de repetibilidade foi estimado como correlação intraclasse, usando-se a seguinte fórmula:

$$
R=\frac{\hat{\sigma}_{\mathrm{v}}^{2}}{\hat{\sigma}_{\mathrm{v}}^{2}+\hat{\sigma}_{\mathrm{e}}^{2}}
$$

onde:

$\mathrm{R}=$ coeficiente de repetibilidade;

$\partial_{\mathrm{v}}^{2}=$ componente de variância de vaca;

$\hat{o}_{\mathrm{e}}^{2}=$ componente de variância atribuída ao erro.

A interpretação genética dos componentes de variância é apresentada por BECKER $^{1}$. O erro padrão dessa estimativa foi calculado pela expressão dada por SWIGER e cols. ${ }^{12}$.

\section{RESULT ADO E DISCUSSÃO}

No presente trabalho foi estudada a produção de leite e duração do periodo de lactação de 851 vacas paridas entre os anos de 1955 a 1972, inclusive. Na TABELA 1 está apresentado o número de observações (N), as médias e coeficientes de variação (C.V.) da produção de leite da primeira à sexta lactação, assim como, a duração do período de lactação. 
TABELA 1 - Produção de leite $\left(\mathrm{kg}_{\mathrm{g}}\right)$ e duraçūo do períado de lactaģāo (dias) por grupo genético e ordem de lactagio.

\begin{tabular}{|c|c|c|c|c|c|}
\hline \multirow{2}{*}{ Lactogão } & \multicolumn{3}{|c|}{$\begin{array}{c}\text { Produçäo de leite } \\
\left(\mathrm{kg}_{\mathrm{g}}\right)\end{array}$} & \multicolumn{2}{|c|}{$\begin{array}{l}\text { Periodo de lactaquão } \\
\text { (dias) }\end{array}$} \\
\hline & $N$ & Média & C.V. (\%) & Média & C.V. (\%) \\
\hline \multicolumn{6}{|c|}{ A. $1 / 2$ Red Poll $\times$ Zebu } \\
\hline Primeira & 200 & 1767 & 20 & 222 & 30 \\
\hline Segunda & 214 & 2054 & 19 & 235 & 23 \\
\hline Terceira & 220 & 2242 & 21 & 243 & 19 \\
\hline Quarta & 213 & 2332 & 19 & 254 & 17 \\
\hline Quinta & 212 & 2323 & 17 & 248 & 17 \\
\hline Sexta & 208 & 2324 & 20 & 254 & 17 \\
\hline \multicolumn{6}{|c|}{ B. 1/4 Red Poll $x 3 / 4$ Guzerá } \\
\hline Primeira & 373 & 1605 & 24 & 251 & 23 \\
\hline Segunda & 345 & 1908 & 21 & 238 & 22 \\
\hline Terceira & 298 & 1986 & 20 & 228 & 23 \\
\hline Quarta & 234 & 2068 & 18 & 234 & 24 \\
\hline Quinta & 180 & 2126 & 19 & 237 & 24 \\
\hline Sexta & 147 & 2193 & 20 & 250 & 23 \\
\hline \multicolumn{6}{|c|}{ C. 5/8 Red Poll x 3/8 Guzerá (Raça Pitangueiras) } \\
\hline Primeira & 206 & 2421 & 16 & 293 & 17 \\
\hline Segunda & 170 & 2649 & 15 & 272 & 21 \\
\hline Terceira & 138 & 2828 & 14 & 278 & 22 \\
\hline Quarta & 110 & 2856 & 15 & 271 & 22 \\
\hline Quinta & 62 & 2979 & 15 & 275 & 22 \\
\hline Sexta & 29 & 2920 & 15 & 270 & 15 \\
\hline
\end{tabular}


As médias encontradas para o período de lactação em vacas 1/4 Red Poll, 1/2 Red Poll e 5/8 Red Poll de 240, 243 e 279 dias, mostram aumento na extensão da lactação de acordo com o aumento da percentagem de genes da raça Red Poll, havendo portanto, possibilidade de se chegar à duração padrão de 305 dias, que é a mais desejável economicamente.

A média geral da duração do período de lactação, em 4192 registros, de 256 dias é relativamente baixa para o rebanho Pitangueiras, porém apenas $32,2 \%$ das lactações são oriundas de bovinos 5/8 Red Poll x 3/8 Zebu.

0 presente valor determinado no rebanho Pitangueiras (256 dias) é inferior à maioria dos valores médios encontrados na literatura estrangeira para as raças zebuínas (274 dias), taurinas (324 dias) e cruzamentos taurino x zebuíno (300 dias). Entretanto, o resultado encontrado é próximo daqueles descritos por CARMO e PRATA ${ }^{3}$ na raça Guzerá, JORDĀO ${ }^{6}$ e LÔBO ${ }^{9}$ nos bovinos Pitangueiras. Pelos resultados, observamos que as raças atualmente exploradas nos trópicos apresentam um período de lactação curto e, talvez, isto seja reflexo de falta de seleção.

É aconselhável que o período de lactação receba maior atenção por parte dos pesquisadores por constituir-se numa medida indireta da capacidade leiteira de uma raça, sendo considerada por alguns, como a característica mais importante na escolha de vacas leiteiras para os trópicos.

A média de produção de leite à primeira lactação, de $1767 \mathrm{~kg}$ para as vacas $1 / 2$ Red Poll com um coeficiente de variação de $20 \%$, fornece um valor médio diário em torno de $7 \mathrm{~kg}$ (TABELA 1). Este resultado é superior ao encontrado por CARNEIRO ${ }^{4}$ nos mestiços Guernsey $x$ Simental e por OHRI e SINGH ${ }^{11}$ no bovino Rathi (resultante do cruzamento de três raças indianas). Por outro lado, estes resultados são inferiores aos obtidos por BRANTON, McDO. WELL e BROWN ${ }^{2}$ nos EE.UU., onde as mes- tiças Sindhi $x$ Jersey, Sindhi $x$ Holandês e Sindhi c Schwyz produziram à primeira lactação, em 256 dias de ordenha, $2239 \mathrm{~kg}$, $2589 \mathrm{~kg}$ e $2300 \mathrm{~kg}$, respectivamente. A superioridade produtiva destes bovinos com relação aos estudados aqui, pode ser devida a melhores sistemas de nutrição e manejo.

As médias de produção de leite à primeira lactação de vacas $1 / 4$ Red Poll e $5 / 8$ Red Poll foram $1605 \mathrm{~kg}$ (C.V. = 24\%) e $2421 \mathrm{~kg}(\mathrm{C} . \mathrm{V} .=16 \%)$, respectivamente. Esta diferença é significativa, mostrando que o aumento na percentagem de genes da raça Red Poll de $37,5 \%$ levou a um aumento de $816 \mathrm{~kg}$ na produção de leite. Nota-se também uma diminuição na variabilidade fenotípica no último grupo, refletida pela magnitude do coeficiente de variação.

Em geral, verifica-se que a maioria das raças leiteiras nos trópicos, atingem a sua maior produção durante a terceira ou quarta lactação. Porém, no presente trabalho as máximas produções de leite foram alcançadas na quarta, quinta e sexta lactação nas vacas 1/2 Red Poll, 5/8 Red Poll e 1/4 Red Poll, respectivamente.

A maturidade produtiva em torno da quarta ou quinta lactação, pode ser explicada pela maior idade à primeira parição, longos intervalos entre partos e menor pressão seletiva aplicada nas vacas criadas nos trópicos.

Os aumentos consecutivos da primeira para a quarta, da primeira para a quinta e da primeira até a sexta lactação, em vacas $1 / 2$ Red Poll, 5/8 Red Poll e 1/4 Red Poll, fo ram de $32 \%, 23 \%$ e $37 \%$, respectivamente. Esta observação vem comprovar os estudos efetuados por outros pesquisadores em bovinos criados em países de clima tropical.

Na TABELA 2 é apresentada a análise de variância mostrando a significância ou não dos efeitos de idade da vaca, época e ano do parto sobre a produção de leite da primeira à quarta lactação, nos três grupos genéticos abordados. 
TABELA 2 - Análise de variância da produção de leite em três grupos genéticos.

\begin{tabular}{|c|c|c|c|c|c|c|}
\hline \multirow{2}{*}{ Fonte de Variação } & \multicolumn{2}{|c|}{ 1/2 Red Poll } & \multicolumn{2}{|c|}{ 1/4 Red Poll } & \multicolumn{2}{|c|}{ 5/8 Red Poll } \\
\hline & G.L. & Q.M. & G.L. & Q.M. & G.L. & Q.M. \\
\hline \multicolumn{7}{|l|}{ A. Primeira Lackação } \\
\hline Idade da vaca & 4 & $203690^{*}$ & 4 & $341833^{*}$ & 4 & 404722 * \\
\hline Epoca do parto & 1 & $498411^{*}$ & 1 & 83391 & 1 & 77655 \\
\hline Ano do parto & 11 & $280395^{*}$ & 17 & $806874^{*}$ & 12 & 303342 * \\
\hline Erro & 183 & 111314 & 379 & 111844 & 188 & 127763 \\
\hline \multicolumn{7}{|c|}{ B. Segunda Lactação } \\
\hline Idade da uaca & 5 & 62583 & 3 & 21870 & 4 & 101455 \\
\hline Epoca do parto & 1 & 348932 & 1 & $989028^{*}$ & 1 & $795264^{*}$ \\
\hline Ano do parto & 12 & $827774^{*}$ & 15 & $932170^{*}$ & 11 & 266724 \\
\hline Erro & 195 & 119476 & 356 & 130827 & 153 & 149205 \\
\hline \multicolumn{7}{|l|}{ C. Terceira Lactagão } \\
\hline Idade da vaca & 5 & 324827 & 4 & 134637 & 5 & 98451 \\
\hline Época do parto & $I$ & 189538 & 1 & 154716 & $l$ & 33320 \\
\hline Ano do parto & 12 & 1037629 & 14 & $433821 *$ & 10 & $358941^{*}$ \\
\hline Erro & 201 & 159173 & 310 & 143692 & 121 & 143601 \\
\hline \multicolumn{7}{|l|}{ D. Quarta Lactação } \\
\hline Idade da vaca & 5 & 193002 & 4 & 306263 & 4 & 88650 \\
\hline Epoca do parto & $I$ & 162633 & $I$ & 251107 & 1 & 14 \\
\hline Ano do parto & 12 & $897101 *$ & 13 & $444454^{*}$ & 9 & $470376^{*}$ \\
\hline Erro & 194 & 139462 & 246 & 154890 & 95 & 157160 \\
\hline
\end{tabular}

- significativo a $\alpha=0,05$

G.L. = graus de liberdade

Q.M. = quadrado médio 
Examinando-se a TABELA 2 verifica-se que a época do parto contribui significativamente para a variação na produção de leite à primeira lactação no grupo genético 1/2 Red Poll, enquanto nas lactações restantes não influenciou. Estes resultados concordam com a maioria dos trabalhos publicados nos países de climas tropical e sub-tropical. Este efeito diferencial de épocas pode ser devido às diferenças de precipitação e temperatura que ocorrem entre as mesmas, já que o agrupamento dos meses em épocas, corresponde exatamente a duas estações distintas. Nos dois outros grupos genéticos não houve contribuição significativa desse efeito para a variabilidade total.

Para os registros da primeira lactação, a idade da vaca contribuiu significativamente para a variabilidade total na produção de leite nos bovinos estudados. Tal efeito é esperado nas vacas de primeiro parto, em virtude do bovino encontrar-se ainda em fase de crescimento corporal e mamário e, por isso, a alimentação vai para a manutenção, crescimento e produção.

0 efeito do ano do parto foi significativo para todos os bovinos estudados e em todas as lactações. Tal efeito pode ser devido à diferença de manejo e alimentação durante os vários anos e em parte à diferença de constituição genética do rebanho no periodo estudado, ou seja, de 1955 a 1972, inclusive.

Os coeficientes de repetibilidade da produção de leite em diferentes lactações dos bovinos estudados são mostrados na TABELA 3.

TABELA 3 - Coeficientes dos componentes de variancia $(K)$ repetibilidade $(R)$ e seus erros pa drōes (E.P.) da produção de leite de três grupos genéticos.

\begin{tabular}{lccr}
\hline Crupos Genéticos & $K$ & $R$ & $E . P$. \\
\hline l/2 Red Poll & 5,5 & 0,15 & 0,03 \\
l/4 Red Poll & 4,1 & 0,36 & 0,03 \\
$5 / 8$ Red Poll & 3,4 & 0,24 & 0,04 \\
\hline
\end{tabular}

A magnitude do coeficiente de repetibilidade depende da variância, devido às diferenças permanentes entre os indivíduos $\mathbf{e}$, devido às diferenças temporárias, decorrentes do ambiente casualmente distribuído entre e dentro dos indivíduos. Isto significa que o coeficiente de repetibilidade inclui toda a variação genética mais a porção de variação de ambiente.

A repetibilidade da produção de leite por lactação é mais alta para lactações consecutivas do que para lactações mais distantes. Isto pode ser explicado considerando que é maior a correlação entre lactações consecutivas e, em parte, pelo cancelamento do efeito da variância de ambiente temporário.

Ao considerar diversas lactações de cada vaca, por exemplo, 4 a 5 , para estimar esse parâmetro fenotípico dentro do rebanho, geralmente encontramos valores em torno de 0,40. Este valor inclui a herdabilidade no sentido amplo, o efeito de interações ge nótipo $x$ ambiente e também algumas dife- renças permanentes de ambiente entre as vacas.

As estimativas da repetibilidade para os grupos genéticos 1/2 Red Poll, 1/4 Red Poll e 5/8 Red Poll acusaram valores baixos, ou seja, de $0,15 \pm 0,03 ; 0,36 \pm 0,03$ e $0,24 \pm 0,04$, respectivamente. Possivelmente o valor de $R=0,36$ para os bovinos $1 / 4$ Red Poll seja decorrente do aumento de variância permanente e redução temporária, em virtude de um maior cancelamento de sinais positivos e negativos.

E necessário mencionar que esses valores estão possivelmente subestimados, devido ao componente $\sigma_{\mathrm{y}}^{2}$ conter o efeito sistemático da ordem de lactações, o qual não fol considerado no presente trabalho.

De acordo com os resultados obtidos, a primeira lactação não deve ser utilizada para eliminação das piores vacas do rebanho, sendo aconselhado, pelos autores, o estudo de um número maior de lactação associadas com outras características de produção. 


\section{CONCLUSŌES}

Com base nos resultados obtidos, julgamos poder chegar às seguintes conclusões:

1. houve aumento na produção de leite e duração do período de lactação à medida que aumentou a percentagem de genes da raça Red Poll;

2. a máxima produção de leite foi alcançada entre a quarta e sexta lactação nos grupos genéticos estudados;

3. a idade da vaca, época e ano do parto influenciaram significativamente a produção de leite;
4. os coeficientes de repetibilidade da produção de leite foram, em geral, de baixa magnitude $(0,15$ a 0,36$)$;

5. na seleção de fêmeas para reposição das matrizes do rebanho, não deve ser considerada apenas a produção de leite à primeira lactação, por ter pouco valor preditivo;

6. a raça Pitangueiras apresentou mais elevada produção leiteira e maior período de lactação quando comparada com os cruzamentos $1 / 2$ Red Poll x $\mathbf{I} / 2$ Zebu e $1 / 4$ Red Poll x 3/4 Guzerá. Por outro lado, as vacas 1/4 Red Poll x 3/4 Guzerá foram inferiores em produção ao $1 / 2 \operatorname{Red~Poll~x~} 1 / 2$ Zebu.

RFMV-A/34

LÔBO, R.B. \& DUARTE, F.A.M. Productive performance of Pitangueiras breed $(5 / 8$ Red Poll $\times 3 / 8$ Guzera) and Red Poll $\times$ Zebu in Brazilian tropical region. Rev. Fac. Med. vet. Zootec. Univ. S. Paulo, 14(2): 315-323, 1977

SUMMARY: Results are presented on productive performance from the I $^{\text {st }}$ to $6^{\text {th }}$ lactations of 234 cows $1 / 2$ Red Poll $x$ 1/2 Zebu, 394 cows $1 / 4$ Red Poll $\times 3 / 4$ Guzeráand 223 cows 5/8 Red Poll $\times 3 / 8$ Guzera (Pitangueiras Breed).A linear programming model and least-square analysis was used to verify the influence of environmental effects on milk production for 256 days at first lactation uas $1767 \mathrm{~kg}$ $(C . V .=20 \%) ; 1605 \mathrm{~kg}($ C.V. $=24 \%) ;$ e $2421 \mathrm{~kg}(\mathrm{C} . \mathrm{V} .=16 \%)$, respectively. The highest production where obtained at $4^{t h}, 6^{\text {th }}$ and $5^{\text {th }}$ lactations with sucessive increase of 32,37 and 23 percent, respecti. vely. The age of cows and the year of calving have significant effect on the milk production at 1 st lactation. The milk production of $1 / 2$ Red Poll $x 1 / 2$ Zebu cows was significantly affected by season of calving. The repeatabilities, as intraclasse correlation were: $0.15 \pm 0.03 ; 0.36 \pm 0.03$ and $0.24 \pm 0.04$ res pectively for the three groups.

UNITERMS: Milk production *; Pitangueiras breed "; Bovine, crossbreeding *.

\section{AGRADECIMENTOS}

Os autores agradecem ao Dr. Warvick Estevam Kerr, pelo incentivo e sugestões apresentadas. Ao Dr. Noé Masotti, pela cuidadosa leitura do manuscrito e observações. Ao Sr. Luiz Antonio Framartino Bezerra pelos serviços de programação e à Srta. Lourdes Aparecida Campos pelos serviços datilográficos. Ao CNPq., FAPESP e OEA, pelo apoio financeiro concedido ao Departamento de Genética. 


\section{REFERENCIAS BIBLIOGRAFICAS}

1 - BECKER, W.A. Manual of procedures in quantitative genetics. 3 ed. Washing ton, Washington State University Press, 1975.

2 - BRANTON, C.; MCDOWELL, R.E.; BROWN M.A. Zebu European crossbreeding as a basis of dairy cattle improvement in the U.S.A. Bull, La. agric. Stn., (114), 1966.

3 - CARMO, J. \& PRATA, H. Estudos sobre o Zebu Leiteiro da Fazenda Experimental de Criação "Getúlio Vargas", em Uberaba, Rio de Janeiro, Ministério da Agricultura - Instituto de Zootecnia, 1961. [Monografia n! 2]

4 - CARNEIRO, G.G. Alguns fatores que influem sobre a produção de leite de vacas mestiças simentais sob o sistema de retiros. Rev. Ceres, Viçosa, 1: 12-21, 104-27, 1939.

5 - HARVEY, W.R. Least squares analysis of data with unequal sub-class numbers. U.S.D.A., ARS, 1960.

6 - JORDÃO, E. Contribuição para o estudo do comportamento leiteiro de um rebanho 5/8 Red Poll e 3/8 Zebu, denominado Pitangueiras. Bol. Ind. Anim., São Paulo, 25: 19-32, 1968.

7 - KASSIR, S.A.; JUMA, K.H.; AL-JAFF, F.H. A further study on dairy characters in Friesian and crossbred cattle in
Iraq. Trop. Agric., 46(4): 359-63, 1969.

8 - KNUDSEN, P.B. \& SOHAEL, A.S. The vom herd: a study of the performance of a mixed Friesian Zebu herd in a tropical environment. Trop. Agric., 47: 189-203, 1970.

9 - LÔBO, L.B. Avaliação genética da produfão leiteira do rebanho Pitangueiras. Ribeirão Preto, 1974. [Tese de Mestrado - Faculdade de Medicina da USP].

10 - MARPLES, H.J.S. \& TRAIL, J.C.M. An analysis of a commercial herd of dairy cattle in Uganda. Trop. Agric., 44: $69-75,1967$

11 - OHRI, S.P. \& SINGH, M. Factors effecting milk production in Rathi cows. Indian vet. J., 48: 252-7, 1971

12 - SWIGER, L.A.; HARVEY, W.R.; EVERSON, D.O.; GREGORY, K.E. The variance of intraclasse correlation involving groups with one observation. Biometrics, 20(4): 218-26, 1964.

13 - TRAIL, J.C.M. \& MARPLES, H.J.S. Friesian cattle in Uganda. Trop. Agric. 45(3): 173-8, 1968.

Recebido para publicação em 30-8-77 Aprovado para publicação em $30-8-77$ 